Exploring corporate social responsibility policies in family owned businesses of Saudi Arabia

Al Sabban, Nadhar

Effat University, Saudi Arabia (yassabbban@effatuniversity.edu.sa)

Al Sabban, Yara

Effat University, Saudi Arabia (nallsabban@effatuniversity.edu.sa)

Rahatullah, Muhammad Khan

Effat University, Saudi Arabia (mkhan@effatuniversity.edu.sa)

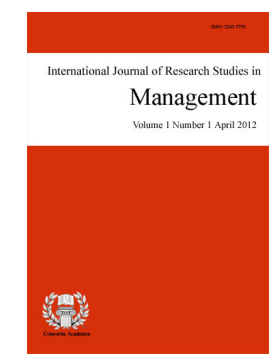

ISSN: $2243-7770$ Online ISSN: 2243-7789

OPEN ACCESS

\title{
Abstract
}

Corporate Social Responsibility is not new to Saudi Arabian cultures. However, it has not been amply evidenced in the literature. This paper utilizing in-depth interviews with the owners of the prominent business houses of the country attempts to explore the CSR initiatives of family owned businesses in the kingdom with a view to understand the policies of such businesses, the impact on business growth and the community.

Keywords: corporate social responsibility; Saudi Arabia; family owned businesses 


\section{Exploring corporate social responsibility policies in family owned businesses of Saudi Arabia}

\section{Introduction}

Corporate Social Responsibility (CSR) is a much known concept in modern business, however, by reading in previously written literature about CSR, no fixed definition ever existed. In one article it was defined as "ensuring that a portion of the economic resources they generate are redistributed from private to public hands in a manner that is both equitable and sustainable" another definition was also "to do well by doing good" (Spector, 2008). While another definition focused more on the financial part of CSR: sacrificing profits in the social interest (Reinhardt \& Stavins, 2010). No matter what definition is used to clarify the CSR concept, the importance of it is what makes it very interesting. In 2005, the U.S Chamber of Commerce, the Hitachi Foundation, and the Boston College Center for Corporate Social Responsibility conducted a survey, which indicated that the importance of CSR comes from the great link between the health of the society and the businesses in that society (Spector, 2008).

In the past few years, business people as well as scholars have been focusing a lot on CSR, as a result, so many arguments and questions were raised around this topic. One argument was around the definition of the goodness that comes under the social responsibility. In other words, CSR depends on doing something good to the society to help improve it, but the question is what if what one business is doing for the society, is not considered as a good favor according to another business (Spector, 2008). Another question was also whether businesses are ready to sacrifice some of their profits in order to help people other than their stakeholders, when maximizing profits for them is one of the businesses' main goals. Moreover, with the competition found in every market nowadays, it is hard for businesses to still use a cut of their profits on a regular basis for the welfare of the society. As well as discovering the circumstances in which it is easier for a business to sacrifice its profits in (Reinhardt \& Stavins, 2010), on the other hand, some researchers focused on the same aspect of financial performance and stakeholders in order to determine the importance of the CSR (Hackert, Tokle, Krumwiede, \& Vokurka, 2012).

Researchers also focused on so many aspects of CSR such as economic, social, and environmental aspects. Previously published papers about CSR included a study of the CSR's perceived and real costs in a theoretical framework; examination of whether there is a relation between superior sustainability practices, how the business is performing financially, and growth; finding a link between CSR, brand equity, and performance, proposing an advice to managers to get involved in CSR and publicize their acts; as well as an examination of the role of national culture in relation with the pollution, recycling, waste reduction, and other environmental initiatives (Hackert et al., 2012).

Even though there is a lack of academic papers that focus on CSR in Saudi Arabia, recent studies have shown that CSR awareness is prevalent (NCB, 2009). The high importance given to CSR in Saudi mainly arises from several reasons, which shall be analyzed. However, some of the reasons do not solely apply to business owned by Saudi families but can overlap to encompass the other businesses model in Saudi.

The initial and most obvious reason for a company to adopt CSR is due to a moral and religious obligation felt by the business owners to help those who are unfortunate. This sense of obligation is part of Islam, the main religion of Saudi Arabia, where charity is considered one of its five pillars (Gravem, 2010). It is strengthened when the company is owned by a single family and not many shareholders (such as a public limited company) as the family feels that they must give to charity and that it could be done though the company. However, CSR is not only used as a way to achieve moral goals but also as a positive reinforcement of their brand image (NCB, 2009). It helps build trust and loyalty between the company and its stakeholders. It has been shown that 
customers are more confident to deal with companies that have adopted CSR and to recommend them to friends and family. Employees tend to be more loyal to the company as they feel they are proud of their work. Also, investors and government branches look upon them favorably and are more inclined to deal with them (NCB, 2009). As the government cannot possibly tackle all the problems, they welcome the assistance from the private sector.

As seen above, CSR is a very importance topic that is being researched by many scholars nowadays. However, even though a lot of CSR aspects have been studied already, there are only few studies talking about CSR in the context of family owned businesses and even fewer deliberating on Saudi family owned businesses. This paper intends to bridge the gap particularly apprising about the CSR activities in the Saudi family owned businesses through an exploratory study.

CSR can be integrated in corporate policies in three main ways (Mandura, 2012). The first method would be to focus on customer-oriented policies such as trying to improve the product but maintaining the same price. However, this method is only applied in a very narrow way in Saudi Arabia. The second method would be to focus on the local natural environment such as using biodegradable materials. The third and final method is the community-oriented goals, which is what most Saudi companies follow. This policy focuses on the local community and is mainly a project-by-project activity. Through surveys, companies have been able to understand what social problems the community feels should be tackled. These social problems listed in order of importance are unemployment, encouraging entrepreneurship and anti-smoking campaigns (NCB, 2009).

The extent of the integration of CSR in corporate policies in to Saudi firms is governed by several factors (Mandura, 2012). While CSR awareness is high, the initiative to put into action has been low as most CSR departments are less than five years old. Notably, CSR departments are not separate entities but are normally a sub branch of another department such as the public affairs department. It should be also considered that while the mid-level managers may have a better knowledge of CSR, the top management may not and as such may consider it to be a tool for propaganda rather than a tool to achieve strategic goals.

There has been a general effort to increase CSR awareness and its use in the corporate world (Gravem, 2010). The Jeddah Chamber of Commerce has created a branch called Jeddah Social Responsibility Center, which aims to assist companies in expanding the CSR programs. The Saudi Arabian General Investment Authority (SAGIA), the King Khaled Foundation, a charity aimed at improving society, and Accountability, a think-tank aimed at increasing sustainability, together created the Saudi Arabian Responsible Competitive Index (SARCI). This index ranks companies based on how well they manage their social and environmental impacts. While the index is voluntary more and more companies are opting to join in. The top three ranked companies in SARCI compete for The King Khalid Award for Responsible Competitiveness, which is aimed at promoting CSR.

There are several companies that have now initiated a CSR programme as part of their company policy. The Abdul Latif Jameel Group, which has been founded by Sheikh Mohammed Abdul Latif, started the Abdul Lateef Jameel Community Initiatives in 2004 with goals to create a more sustainable community (Tharawat, 2012). Through the Toyota dealership, the family did not just want to sell cars but help the community to acquire them to start their own businesses. In 2007, Bab Rizq was established as part of the Community Initiatives and was targeted at supporting entrepreneurship in the community. This was done through many different ways including providing a taxi or truck for an unemployed person to be able to earn a living or interest free loans to women who had ideas for useful household products. The famous Albaik restaurant which is owned by the AbuGhazaleh family have always supported the community through sponsoring many campaigns such as an anti-littering campaign, a climb of Mount Everest to combat cancer and a removal of graffiti in the local neighborhoods. These campaigns, while smaller in size compared to the Abdul Lateef Jameel Community Initiatives, have been very rewarding in supporting the brand image within the local communities (Ramady, 2010)

In conclusion, it can be said that CSR is still in an early stage of development, which bears a strong 
resemblance to the state of the private sector development. There is a notion that CSR is in a way a philanthropic action but is restricted to local propaganda driven goals and not long term corporate goals. In this sense, CSR will not be able to accomplish its full goals for both the company and their stakeholders, unless the theory is properly taught and communicated throughout the company.

\subsection{The Gaps:}

The above discussion shows that there is a rich body of literature on CSR in general and the CSR initiatives in Saudi Arabia by family owned businesses in particular. However what we don't find is the information that what role do these CSR programs play in the family owned brands development. Similarly there is also a dearth of information on the role of these CSR programs in economic development of the Kingdom.

\subsection{Research Questions:}

The aforementioned literature and the gaps identified lead to the following questions that need to be investigated.

\section{What is the role of CSR programs in family owned brands development?}

This question will aim to understand the dynamics of the CSR programs in family owned businesses in Saudi Arabia by detailed qualitative research to come to the result identifying their particular role in brand development.

\section{What is the impact of CSR programs on family owned business?}

It is important to understand the value of the CSR campaigns by the family owned businesses in Saudi Arabia. It is because of the fact that the major business model prevailing in the Kingdom is family owned. More than $70 \%$ of the top 100 businesses in the Kingdom are family owned (Arab news, March $14^{\text {th }} 2013$ ).

\section{Research Method}

The debate in current times about the advantages and disadvantages of qualitative and quantitative research methods has been ongoing in many of the social sciences. While many of the arguments supporting the different methods have completely opposed each other, there is an up and coming view between many scholars who have decided that one method integrate the different sides. Bryman (1988) was a main supporter of merging the two techniques to be able to benefit from "the best of both sides". Many have dismissed this argument as the quantitative method is considered to be more scientific and unbiased (Hughes, 1997).

Before being able to assess whether the quantitative or qualitative method is more successful, one must look what research consists of. It is considered that quantitative research is more pragmatic while qualitative is considered to be more open to unregulated interpretations (Bernard, 1994). For example, a survey is considered by many as quantitative research, while on further observation it can been seen that it has many links to qualitative research. This presumption arises from the fact that the numeric data, which is collected from surveys, is automatically codified into a numeric format. This argument is considered to be false as surveys can have open-ended questions, which allow for qualitative data to be collected, that allow for a more critical analysis of the subject matter. These matters are all considered before it is decided to take a qualitative or quantitative approach to the research (Creswell, 1994).

Quantitative research has many features that distinct it from qualitative research. The most prominent feature is the existence of control of the survey. This feature is significant when a study attempts to find out why a certain issue arises and the required factors. It allows the surveyor to eliminate any vague answers and separate the unrelated factors to the matter at hand. Another significant element is the analysis and clear definition of the subject in question where the actual question of the survey is defined to show clearly what is the aim of the study. 
A clear difference between the two methods is that if quantitative research is repeated, the results should be almost identical to the previous attempt. This consistency makes many advocate this study (Burns, 2000). However, this method has many disadvantages as human behavior is intricate to be limited into a certain number of options. Thus it may provide distorted result. This limitation does not allow for the different responses based on issues like morals.

There are many arguments supporting the use of qualitative methods. Because of close researcher involvement, the researcher gains an insider's view of the field. This allows the researcher to find issues that are often missed (such as subtleties and complexities) by other methods. Because statistics are not used, but rather qualitative research uses a more descriptive, narrative style, this research might be of particular benefit to the practitioner as she or he could turn to qualitative reports in order to examine forms of knowledge that might otherwise be unavailable, thereby gaining new insight (Burns, 2000).

Quantitative research also has many disadvantages. Due to such a wide range of answers possible, it is often considered to be unreliable, especially when there is no method of verification. It is also considered that due to the different factors that are studied when making an answer, it is impossible to be able to replicate a study with the same set result. Another issue advocating against this method is that the process to collect and analyze the data is tedious.

When analyzing corporate social responsibility in Saudi Arabia, there are several factors that must be considered first. The most important factor that must be considered is the limited amount of literature available on the subject especially in a detailed aspect such as CSR in family owned businesses. This factor in itself does not allow for such a wide ranged analysis.

As is the case with most of the initial studies, all of the research done is of a quantitative approach. Quantitative approaches are always used as a starting point as they allow the researcher to establish the basic facts of the study, which can later be built upon. The quantitative approach also enables the researcher to draw the basic conclusions, which would show in what direction the research to continue in. Starting with a qualitative approach would result in such a wide range of results, which cannot be collated in to viable data to proceed upon.

Another aspect that must be considered is the culture and tradition of the subjects of the survey. Saudi Arabia is a very conservative and traditional society which is not inclined to discuss their matters publicly especially problems. This is because it is frowned upon to discuss problems and concerns openly. Accordingly, using a qualitative method may not bring viable results as people would either not give any answers or give very limited answers. A quantitative approach would encourage people answer, as there are already available options.

As can be seen, due to the limited available data and studies, it is not possible to analyze in depth the different methods used in the research. Corporate social responsibility within companies in itself must first be developed further in Saudi Arabia before any more studies can be carried out. Once it becomes a more established concept, it would open more doors to more research to be done on the subject and how the research is done.

\section{Results}

In order to collect valuable data to complete this paper, it was important to understand how family owned businesses in the kingdom operate, and how does CSR impact those businesses. So, interviews have been conducted with family members from 6 of the most successful family owned businesses in Saudi Arabia:

\subsection{Fetaihi Holding Group}

Ahmad Hossain Abdullah Fitaihi founded Fitaihi group in 1878. The company is a public listed company; however, the family owns $51 \%$ of its shares. Fitaihi manufactures gold, silver, and jewelry, along with other 
related accessories, watches, gifts, and clothes for males, females and kids. Moreover, Fitaihi launched and is managing medical centers, trading in medical equipment \& machines. Fitaihi \& Co. owns $100 \%$ of the following secondary corporations: Fitaihi center Riyadh, Fitaihi Wholesale center Jeddah, International Marina Be Co. Geneva, Milan, New York Marina Be. London, Fitaihi Junior Jeddah and Marina Be Jeddah. Fitaihi group is national company only in Saudi Arabia. The sales turnover in Fitaihi was: 55.01. However, the group has around 12000 employees and it is ranked as the 85/100 in Saudi Arabia.

\subsection{Abdul Lateef Jameel Group}

Abdullatif Jameel Group is a family owned business and it's one of the top 10 privately owned Saudi companies. The major activities that ALJ group provide are consumer goods, financial services, health care, Leisure and Tourism, real state, services and transport like Automotive, Passenger Cars, Agents and Dealers (Primary Industry), Auto Parts and Accessories, Agents and Distributors and Repair and Maintenance Services. In addition, the geographic spread of ALJ group in Middle East, UK, Central Asia, Turkey and China. On the other hand, ALJ group ranked 17th the last year in Saudi Arabia and they have 8,000 employees in their business and their sales turnover was $5.30 \mathrm{bn}$ in the last year.

\subsection{AliReza Holding Co.}

Conceived in 1997, Alireza Holding Co, a privately held company, has gone on to grow successful businesses in sectors ranging from retail, electronics, fashion, insurance, and motor sports. There are 250+ employees across the Middle East with operations in countries such as Lebanon, KSA, Egypt, UAE, Qatar, and Bahrain. Alireza Holding Co, works with companies such as Henkel, Campomatic, Beats By Dre, Mophie, Yosi Samra, in addition to their own private label brands including but not limited to: Tokyo Games, I.ZONE and ICON. Alireza multi-brand, multi-market company portfolio brings leading retail concepts and industrial solutions to the Middle East market.

The main questions asked in the interviews, revolved around the following areas:

$>$ The start of CSR practices in the company

$>\quad$ The difference between CSR practices in Saudi Arabia and internationally

$>\quad$ Role of CSR on the business

$>$ Impact of CSR activates on the business

$>$ The major projects by the business for CSR

\section{Discussion}

The first area of discussion was the time when the business started its CSR activities. It has been found that the CSR has been present in the businesses for long time. The family members have been actively involved in acts of charity, social service, community development programs, and other philanthropic acts from very beginning of their businesses as discussed below.

In the Fitaihi group the founder started CSR practice long before it was known in business as he loved to help people and to give back to the society. Fitaihi have been sending 8-10 boys to complete their education in Egypt and USA every year, in addition to investing in different colleges, schools, and universities. The Abdul Lateef Jameel group, Ali Reza, Juffali and Bin Zagr have also been helping and assisting the orphans and orphanages for long time. However, none of the companies interviewed have structured the CSR practices till late and some have not done it at all. They keep on practicing it as need arises. The Bahrawi's have also been engaged in the act on collective family basis. They collectively assist different projects. Some of the businesses 
like Abdul Lateef Jameel perform CSR from the zakat monies, which are a specified amount of a Muslim's wealth that should be given to particular recipients when the wealth reaches a designated minimal amount for a full cycle of a lunar year. Zakat is an obligation from Muslims to their brothers and sisters in need (Abdullah, et al., 2012).

The family members are motivated by the cultural practices and norms that guide them to enter into such activities. There is also a race between people for the acts of kindness to fellow citizens and economically underprivileged.

The family members when asked about the differences in approach in performance and implementation of CSR activities locally and internationally; all agreed and suggested that there is a huge difference between the Saudi and western approach. In Saudi Arabia according to all interviewed family members the CSR is personal act by each member. It could be in shape of the alms, charity, educational assistance to individuals, helping poor get married or start a micro business etc. Whereas, in Western world according to

It has surfaced from the interviews that in Saudi Arabia the main acts of CSR are considered to be financial assistance or through money. There is little emphasis on development of communities in certain sectors or performance of CSR on institutions of social welfare. It is because the social welfare institutions and many others are considered to be the responsibility of the Government, said the family members from Bahrawi, Ali Reza and Bin Zagr. There is also little emphasis on long term corporate strategy by either of the businesses interviewed. Whereas, it is observed in the literature that, in the western world, CSR is integral part of the businesses' corporate strategy. It is in stark contrast to Saudi non family businesses as well. The corporate firms like Saudi Telecom, Saudi Electricity, Aramco (Arab American Company) and others have a comprehensive CSR strategy. The family members interviewed from Ali Reza, Jaffali, Fetaihi, and Abdul Lateef Jameel informed that they are now developing a long term corporate strategy for CSR that would become part of their strategic plans.

The Bahrawi, Abdul Lateef Jameel, Jaffali and Fetaihi groups emphasized more on individual human development through assistance in education and or startup of micro businesses for a specific period of time. Whereas; on the other hand, Ali Reza and Bin Zagr had been performing similar activities nationally and internationally for the past 50 years.

According to all the interviewees the CSR is now becoming and occupying central stage in their philanthropic initiatives.

\section{Conclusion}

Saudi Arabian family owned businesses are actively involved in CSR activates locally, and some are even doing it internationally, which all businesses interviewed agreed that it is completely different procedure. The businesses family members agreed that CSR activates carry a very important role for them of giving back to the society. It is also undeniable that CSR can be a very strong marketing tool. CSR has been there for a long time, yet, only few businesses structured the process of practicing it. For that reason, businesses are now developing a long-term corporate strategy for CSR, in order to integrate it into their strategic plans. From the discussion, it is clear that Saudi businesses are aware of the importance of CSR activates, and the value it adds to their businesses, which is the reason why they are already putting more emphasis on it than ever before.

\subsection{Recommendations}

As discussed, family owned businesses are aware of the huge value CSR activities add to their businesses, however, only few spent the time to structure the practices. Thus, it is recommended that other businesses do the same to make the procedure easier.

When that is done, another study is recommended in order to compare and contrast the different structures in family owned businesses. 


\subsection{Limitations}

The completion of this paper was not an easy task, as there were few challenges faced. One of the main difficulties was reaching the family members of the different businesses. However, they were all happy to conduct the interviews later on. Another challenge was the time constraint, as it was needed to conduct the interviews and complete the paper in a very short time.

\section{References}

A Family Business Setting Standards in Job Creation. (2012). Tharwat Magazine, 73-75.

Close-Up Media Inc. (2013, Febuary 18). MGM resorts international garners national award for corporate social responsibility best practices. Fine Arts and Music Collection .

Close-Up Media, Inc. (2012, April 23). PR news names 'firefighters for safer communities' as finalist in the CSR awards for social good. Fine Arts and Music Collection .

Gravem, M. (2010). CSR in Saudi Arabia. Oslo: Rolf Ottesen Grafisk Produksjon AS.

Hackert, A., Tokle, J., Krumwiede, D., \& Vokurka, R. (2012). Global corporate social responsibility practices and cultural dimensions. SAM Advanced Management Journal, 33-41.

Mandurah, S., Khatib, J., \& Al-Sabaan, S. (2012). Corporate social responsibility among Saudi Arabian firms: An empirical investigation. The Journal of Applied Business Research , 28(5), 1049-1058.

Ramady, M. A. (2010). The challenges ahead. In M. A. Ramady, The Saudi Arabia Economy (pp. 479-488). Springer US.

Reinhardt, F., \& Stavins, R. (2010). Corporate social responsibility, business strategy, and the environment. Oxford Review of Economic Policy , 26(2), 164-181. http://dx.doi.org/10.1093/oxrep/grq008

Shalaby, K. (2008). The kingdom of Saudi Arabia . In B. Ibrahim, \& D. Sherif, From charity to social change (pp. 65-79).

Spector, B. (2008, June 9). Roots of the corporate social responsibility movement. Enterprise and Society, 315-336.

The National Commercial Bank. (2009). Corporate social responsibility in the kingdom of Saudi Arabia 2009. 